\title{
Relative readings of superlatives: Scope or focus?*
}

\author{
Barbara Tomaszewicz \\ Tilburg University
}

\begin{abstract}
I provide an analysis of the relative readings of superlatives on which the superlative morpheme -est is more constrained at LF than previously argued, yet the range of superlative readings available cross-linguistically is still accounted for. I argue that -est scopes outside the superlative DP only when it is necessary for the derivation of a particular reading. I also provide empirical arguments that the focus structure of the sentence must be included in the LF representation of relative readings. In English, where -est only scopes DP-internally, we correctly predict the optionality of focus for relative readings. In Polish, where -est can also scope DP-externally, focus can be obligatory to disambiguate between the different LFs.
\end{abstract}

Keywords: superlative -est, scope, Scope Economy, focus association, presupposition

\section{Introduction}

A sentence containing a superlative expression, such as the most expensive cake in (1), can receive different interpretations depending on how the comparison class is specified with respect to the different constituents of the sentence (Heim 1985; Szabolcsi 1986; Gawron 1995; a.o.). When the comparison class is established with respect to the superlative DP itself, the absolute reading arises, (1a). The comparison set contains cakes that are relevant in the context without consideration of who has bought or received them. On the relative readings, (1b-c), the comparison class is determined with respect to one of the sentence constituents, John in (1b) and Mary in (1c).

* I would like to thank Roumi Pancheva, Yael Sharvit and Anna Szabolcsi for their comments, questions and suggestions that helped improve this paper. My thanks also go to Maria Luisa Zubizarreta, Barry Schein, Elsi Kaiser and Thomas Seifrid, as well as to the audience of SALT 25. The errors are all mine. 
Relative readings of superlatives

(1) John bought Mary the most expensive cake.

a. 'John bought Mary the cake that was more expensive than any other (relevant) cake.' Absolute Reading

b. 'John bought Mary a more expensive cake than any other (relevant) person did.' Relative Reading

c. 'John bought Mary a more expensive cake than he bought for any other (relevant) person.' Relative Reading

Focus has a disambiguating effect on the relative readings (Ross 1964; Jackendoff 1972; Szabolcsi 1986; Heim 1999; Farkas and É. Kiss 2000; Sharvit and Stateva 2002; a.o.). The placement of focus on John, (2a), facilitates the relative reading in (1b) and precludes the relative reading in (1c). Focus on Mary, (2a), disambiguates in favor of the reading in (1c). Note that the presence of focus does not exclude the availability of the absolute reading, (1a).

(2) a. $[\mathrm{JOHN}]_{\mathrm{F}}$ bought Mary the most expensive cake.

b. John bought [MAry]F the most expensive cake.

The focus facts alone suggest that F-marking should not be ignored in the derivation of relative readings, however, the data in (3) suggests otherwise. In (3) the elements that are not prosodically prominent, who or its trace, are relevant for the determination of the comparison class. Szabolcsi 1986 and Heim 1999 conclude that the lack of correspondence between prosodic focus and putative semantic focus on who or its trace in (3) provides evidence that focus is not needed for the derivation of relative readings.

(3) We should congratulate the boy who got the most expensive $[\mathrm{CAKE}]_{\mathrm{F}}$.

Szabolcsi 1986 and Heim 1985, 1999 propose that the different readings of a superlative sentence are derived by allowing the superlative morpheme -est, a quantifier over degrees with the semantics in (4), ${ }^{1}$ to take different scope within the clause. When -est scopes DP-internally, (5a), the absolute reading is derived. When -est takes scope at the clausal level and its individual argument is saturated by John, as in (5b), the comparison set contains the relevant individuals who bought cakes for Mary and, accordingly, the relative reading in (1b) is derived. When Mary saturates -est's third argument, (5c), the relative reading in (1c) is derived. Note that the superlative DP is considered to be indefinite at LF, $(5 b-c)$.

${ }^{1}$ The lexical entry in (4) requires the assumption that gradable predicates are downward monotonic:

(i) A relation $R$ between objects $x$ and degrees $d$, $d$ ' is downward monotonic iff: $\forall x \forall d \forall d^{\prime}\left[R(x, d)=1 \wedge d^{\prime}<d \rightarrow R\left(x, d^{\prime}\right)\right]$ 
$\llbracket$-est $\rrbracket=\lambda C_{\langle\mathrm{e}, \mathrm{t}\rangle} . \lambda D_{\langle\mathrm{d}, \mathrm{et}\rangle} \cdot \lambda x_{\mathrm{e}} . \exists d[D(d)(x) \wedge \forall y \in C[y \neq x \rightarrow \neg(D(d)(y))]]$

Presuppositions: $x \in C, \forall y[y \in C \rightarrow \exists d[D(d)(y)]]$.

(Heim 1999)

(5) a. John bought Mary [DP the [[-est $C] \lambda d$. $d$-expensive cake]] $C \subseteq\{x: \exists d[x$ is a $d$-expensive cake $]\}$ Absolute (1a)

b. John [-est $C$ ] $\lambda d$. $\lambda x$. $x$ bought Mary [DP a $d$-expensive cake] $C \subseteq\{x: \exists d[x$ bought Mary a $d$-expensive cake $]\} \quad$ Relative (1b)

c. Mary [-est $C$ ] $\lambda d$. $\lambda x$. John bought $x$ [DP a $d$-expensive cake] $C \subseteq\{x: \exists d[$ John bought $x$ a $d$-expensive cake] $\}$ Relative (1c)

The scope analysis does not require that the effect of focus be represented at LF for the computation of the contents of the comparison set $C$. For Szabolcsi 1986 and Heim 1999 this is an advantage, because for the derivation of the relative reading of (3) they can avoid positing focus on a prosodically unmarked element: who or its trace. For this view, however, the Polish counterpart of (3) presents a puzzle with neutral intonation, as in (6a), the reading on which the comparison involves those individuals who got cakes of some price is missing. This reading only obtains if there is focus on the superlative adjective, $(6 \mathrm{~b})$.

(6) Powinniśmy pogratulować chłopcu, ...

we-should congratulate boy

'We should congratulate the boy...

a. który dostał najdroższe ciastko. who got most-expensive Acc $_{\text {cake }}$ cacc $_{\text {A }}$ '... who got a more expensive cake than any other thing he got.'

b. który dostał [najDROŻsze $]_{\mathrm{F}}$ ciastko. who got most-expensive ${ }_{A c c}$ cake $_{A c c}$ '... who got a more expensive cake than any other boy.'

Without the focus on the superlative adjective, the sentence in (6a) receives a relative reading - absent in English - on which the relevant things that the boy received are compared in terms of their price. On this reading the comparison class $C$ is set with respect to the DP-internal constituent, the NP cake, and contains predicates: the predicate cake and the relevant alternatives to cake which are predicates true of things of some price that John bought for Mary, (7).

(7) cake [-est $C] \lambda d$. $\lambda f$. $\exists x$ John bought Mary [DP $d$-expensive $f(x)]$

$C \subseteq\{f: \exists d \exists x[$ John bought Mary $x \wedge x$ is $d$-expensive $\wedge f(x)]\}$

DP-Internal Relative Reading

'John bought Mary a more expensive cake than any other (relevant) thing he bought her.' 
Relative readings of superlatives

The semantics for -est in (4) requires the third argument to be of type $e$, but if there is no individual denoting constituent that could move, the entry in (4) can be modified to be cross-categorial, as in (8) (a cross-categorial -est is proposed for English in Kotek et al. 2011).

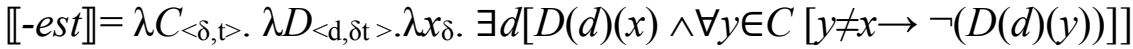

$$
\begin{aligned}
& \text { Presuppositions: } x_{\delta} \in C<\delta, \triangleright, \forall y_{\delta}\left[y_{\delta} \in C<\delta, \downarrow \rightarrow \exists d[D(d)(y)]\right] \text {. }
\end{aligned}
$$

The scope analysis predicts that the reading derived in (7) should also be available for the English sentence in (1), but in Pancheva and Tomaszewicz 2012 we observe that DP-internal relative readings are available only in the absence of the definite determiner in the superlative DP (accordingly, they are never available in a language like English where the definite determiner is obligatory with superlatives). We propose that -est can scope DP-externally only in the absence of the in the superlative DP. In a language like Polish which does not have articles and superlative DPs are always (morphologically) indefinite, -est should always be able to scope DP-externally. The fact that focus is obligatory on the adjective in (6b) for the DP-external relative reading to arise is also a puzzle for our analysis.

In this paper, I extend our approach in Pancheva and Tomaszewicz 2012 by postulating that in the absence of the definite determiner in the superlative DP, -est is able to scope out, but only when allowed by Scope Economy. I show that Scope Economy precludes -est from taking DP-external scope for the derivation of relative readings set with respect to DP-external constituents (John or Mary in (1)). Thus, the focus in (6b) serves to indicate that -est is to be interpreted DP-internally although the absence of the definite determiner allows for DP-external scope. On this analysis, -est is more constrained at LF than previously argued, yet the range of superlative readings available cross-linguistically is still accounted for (Tomaszewicz 2015b).

\section{The syntax of the superlative morpheme}

On the scope theory, the different readings of superlatives are treated as a genuine ambiguity, but as observed by Heim 1999 the movement of -est out of the superlative DP is not necessary to derive DP-external relative readings. As noted in the previous section, the different readings result from different specifications of the comparison class $C$. I will now illustrate that the truth conditions of a superlative sentence change both when the scope of -est changes (which necessarily affects $C$ due to -est's presuppositions, (4)) and when the scope of -est remains the same but the specification of $C$ changes due to the contextual constraints on what counts as being relevant.

In (9) the truth conditions of the absolute reading are derived. In (10) DPexternal scope derives the relative reading set with respect to John (the comparison 
is between the relevant individuals who bought cakes for Mary). In (11) the same relative reading is derived by keeping -est DP-internally and adding a restriction on the comparison class $C$, which being a domain variable is naturally subject to contextual constraints.

(9) a. John bought Mary [DP the [-est $C]$ [NP $2 t_{2}$-expensive cake]]

b. $\llbracket \mathrm{NP} \rrbracket=\lambda d \lambda x[x$ is a cake $\wedge x$ is $d$-expensive $]$

c. $C \subseteq\{x: \exists d[x$ is a $d$-expensive cake $]\}$

d. $\llbracket \mathrm{DP} \rrbracket=x \exists d[x$ is a $d$-expensive cake $\wedge \forall y[y \in C \wedge y \neq x \rightarrow \neg[y$ is a $d$ expensive cake]]]

e. $\llbracket(9 a) \rrbracket=1$ iff John bought Mary the unique cake of a certain price such that no other cake in the comparison class of relevant cakes of a certain price is more expensive than that cake

(10) a. [TP1 John [TP2[-est $C]$ [TP3 $21 t_{1}$ bought Mary [DP a [NP $t_{2}$-expensive cake]]]]

b. $\llbracket \mathrm{TP}_{3} \rrbracket=\lambda d \lambda x[x$ bought Mary a $d$-expensive cake $]$

c. $C \subseteq\{x: \exists d[x$ bought Mary a $d$-expensive cake $]\}$

d. $\llbracket \mathrm{TP}_{1} \rrbracket=\exists d[$ John bought Mary a $d$-expensive cake $\wedge \forall y[y \in C \wedge y \neq$ John $\rightarrow \neg[y$ bought Mary a $d$-expensive cake $]]$

e. $\llbracket(10 \mathrm{a}) \rrbracket=1$ iff there is a degree $d$ such that John bought Mary a cake of price $d$ and no other individual in the comparison class of relevant people who bought Mary cakes of a certain price bought her a cake of price $d$

(11) a. John bought Mary [DP the [-est $C]$ [NP $2 t_{2}$-expensive cake]]

b. $C \subseteq\{x: \exists d \exists y[x$ is a $d$-expensive cake $\wedge y$ bought Mary $x\}$

c. $\llbracket(11 \mathrm{a}) \rrbracket=1$ iff John bought Mary the unique cake of a certain price such that no other cake in the comparison class of relevant cakes of a certain price that someone bought for Mary is more expensive than that cake

The results of comparing relevant cake buyers in terms of the price of their cakes, (10e), and the results of comparing cakes bought by relevant people, (11c), are truth-conditionally equivalent. Since relative readings can be derived without the movement of -est outside the DP, Farkas and Kiss 2000, Sharvit and Stateva 2002, Coppock and Beaver 2014 argue that this movement is, in fact, not allowed.

This approach is right for languages where the definite determiner is obligatory in the superlative DP, but for languages where indefinite superlative DPs are possible, it fails to predict the existence of DP-internal relative readings, which cannot be derived without the movement of -est outside the DP (Pancheva and Tomaszewicz 2012). To illustrate this point consider (12a-b). With DP-internal - 
Relative readings of superlatives

est, the members of $C$ are cakes and it is not possible to replace this set with a set of alternatives to cakes by adding that the individuals in $C$ have some other property $f,(12 b)$.

(12) a. John bought Mary [DP the [-est $C$ ] [NP $2 t_{2}$-expensive cake]]

b. $C \subseteq\{x: \exists d \exists f[x$ is a $d$-expensive cake $\wedge f(x)]\}$

It needs to be the case that cross-linguistically there are two ways to relative readings: by scoping -est DP-externally, and by keeping -est DP-internally and constraining the specification of $C .^{2}$ Note now that neither derivation requires reference to focus. On the DP-internal approach, focus effects are a subset of the contextual effects on the specification of $C$. On the scope theory, focus helps to choose between the different LFs for the different relative readings.

The empirical facts from Polish presented in (6a-b) suggest that focus is not merely an optional indicator of -est's scope. The context in (6a) is not enough to specify the DP-external relative reading on which different boys are compared. For this reading the focus on the superlative adjective is necessary (6b). Moreover, the focus on the superlative adjective in (6b) is incompatible with the DP-internal relative reading of $(6 a)$.

As shown above in (12), the derivation of the DP-internal relative reading requires DP-external scope of -est for the proper specification of the comparison class, i.e., predicates alternative to the predicate cake, (7). The fact that with the focus on the superlative adjective, the DP-internal relative reading is unavailable indicates that in (6b) the DP-external scope for -est is impossible. Therefore, the DP-external relative reading that this sentence has must be derived with -est remaining DP-internally as in (11). This is surprising given that the scope analysis predicts that once -est is able to scope outside the DP in a language (i.e., in the absence of the definite determiner), both DP-external and DP-internal relative readings can be derived by scope.

\footnotetext{
${ }^{2}$ In Tomaszewicz 2015a,b I discuss and refute an alternative to the approach in Pancheva and Tomaszewicz 2012 according to which what constrains the derivation of DP-internal relative readings in some languages is not the constraints on the movement of -est, but the constraints on the movement of the NP/DP subconstituent of the superlative DP (e.g. constraints on the movement of cake in (7)). I conclude that definite superlative DPs are not islands for the movement of a nominal subconstituent, because with indefinite superlatives we do not find cases where -est is free to scope DP-externally but a nominal subconstituent is not.
} 
Why is DP-external scope possible for (6a) so that the DP-internal relative reading can be derived, (13a), but why is DP-external scope not possible for (6b) for the derivation of the DP-external relative reading, $(13 \mathrm{~b})$ ?

a. DP-Internal Relative Readings in Polish [NP/DP ...][Tт [-est $\boldsymbol{C}] 21$ [

b. DP-External Relative Readings in Polish

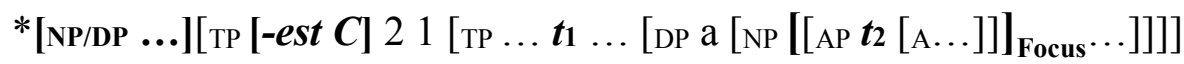

In the next section I propose that Scope Economy might explain why (13b) is excluded, i.e., why the DP-external scope of -est is precluded for DP-external relative readings. Additionally, to account for the fact that in (6b) focus is obligatory to indicate DP-internal scope of -est, I argue in Section 4 that in the derivation of relative readings focus must be encoded at LF. I show how the focus on the superlative adjective has an indirect effect on the comparison class $C$ when -est remains DP-internal.

\section{Scope Economy constraining -est}

I argue that DP-external relative readings are derived with DP-internal -est both with definite and indefinite DPs, i.e., both in English and Polish. The derivation of DP-external relative readings by scoping -est out of an indefinite DP is precluded by Scope Economy.

When -est takes DP-external scope, it is required that a constituent of the right type to saturate its third argument has QRed to the edge of the clause. In (10a), [-est $C]$ is of type $\langle\langle d,\langle e, t\rangle\rangle,\langle e, t\rangle\rangle$ and an individual denoting constituent, the subject John, QRs to the edge of the clause; then [-est C] QRs out of the NP and tucks in right below John. ${ }^{3}$ In (7), [-est C] is of type $\langle\langle d,\langle\langle e, t\rangle, t\rangle\rangle,\langle\langle e, t\rangle, t\rangle\rangle$ and a property denoting constituent, the head NP cake, undergoes QR. The movement of the NP/DP in both cases is not driven by a type-mismatch in the in-situ position, hence it is not obligatory. In both cases type-wise there is nothing that prevents the in-situ composition of those constituents; the sole purpose of the movement is the derivation of the relative reading. Therefore, this movement is an instance of optional QR, a QR operation that applies only when it is necessary to derive an interpretation that a sentence would otherwise not have.

\footnotetext{
${ }^{3}$ When -est takes sentential scope, it is required to tuck in because of its semantics. -est's sister node needs to be of type $\langle d$,et $>$ to saturate its second argument, while the raised individual argument needs to saturate its third argument. The movement of the comparative morpheme -er on its 3-place semantics also requires tucking in (Bhatt and Takahashi 2007).
} 
Relative readings of superlatives

It should first be noted that the movement of -est is an instance of optional QR as well. Type-wise [-est $C]$ and the adjective (type $\langle d,\langle e, t\rangle\rangle)$ can combine in-situ (as noted in e.g., Bošković and Gajewski 2009). The presuppositions in (4) could technically be met; for example, $C$ would consist of the relevant objects that have a certain price, (14b). For the intended readings, however, we need to include the noun as well so that $C$ consists specifically of cakes of some price and not of any objects that have a price - on none of the readings of (1) is the adjective most expensive interpreted intersectively (the most expensive cake in (1a-c) is not the most expensive item and a cake (Heim 1999; Cinque 2010)).
a. John bought Mary [DP the [NP [AP[-est $C]$ expensive] cake]]
b. $C \subseteq\{x: \exists d[x$ is $d$-expensive $]\}$

It has been argued that $\mathrm{QR}$ operations that do not result in a truth-conditional difference are excluded by principles of economy (Fox's 2000 Scope Economy, Reinhart's 2006 Interface Economy). The 'short' movement of -est to the edge of the DP results in a change in the truth conditions (i.e., it prevents the interpretation in (14b) as described above); therefore it is not precluded by scope economy. The 'long' movement of -est outside of the DP is preceded by the QR of a constituent that can saturate its third argument, so the economy constraints first apply to the QR of that constituent. If the principle of Scope Economy sees the first movement as semantically vacuous, it will block further derivation.

In the case of the DP-external relative reading, this first intermediate step on its own does not result in a new interpretation. The QR of John in (15a) has no semantic effect $-(15 \mathrm{a})$ receives the absolute reading since the comparison class is as in (15b) (alternatively, [-est $C$ ] may remain within the AP and the comparison class is as in (14b)). For Scope Economy there is no truth conditional difference between the LF prior to the movement of John and the LF in (15a), because the movement has no effect on C. Thus, the movement of John violates Scope Economy and this derivation is blocked.

\section{(15) Derivation of DP-External Relative Reading}
a. $1^{\text {st }}$ Step
$\mathrm{John}_{1}$ [те $t_{1}$ bought Mary [DP a [-est $\left.C\right]_{2}\left[\mathrm{NP} d_{2}\right.$-expensive cake]]
b. $C \subseteq\{x: \exists d[x$ is a $d$-expensive cake $]\}$
c. $\quad 2^{\text {nd }}$ Step
$\mathrm{John}_{1}$ [-est $\left.C\right]_{2}\left[\mathrm{TP} t_{1}\right.$ bought Mary [DP a [NP $d_{2}$-expensive cake]]]
d. $C \subseteq\{x: \exists d[x$ bought Mary a $d$-expensive cake $]\}$

In (16a), however, the trace of cake is interpreted as a variable that is free within the DP. The denotation of the NP is assignment dependent, (16b). The truth 
conditions of (16a) are not right for the DP-internal relative reading, thus the derivation cannot stop here. Further derivation is allowed because for Scope Economy there is a truth conditional difference: $C$ changed from the set of cakes of some price (as in (9c)) to the set of individuals $x$ such that there is a degree to which $x$ is expensive and there is a predicate true of $x,(16 \mathrm{c})$. For the interpretation of the whole LF in (16a), cake has to be interpreted downstairs, ${ }^{4}$ but for the computation of the presupposition that specifies $C$ the trace is interpreted as a variable over predicates. (We need to assume that assignment functions can range over predicates, not just individuals, because $\mathrm{g}(1)$ in $(16 \mathrm{~b})$ is of type $<\mathrm{e}, \mathrm{t}>$.)

\section{(16) Derivation of Relative-2}
a. $1^{\text {st }}$ Step cake $_{1}[\text { John bought Mary [DP a [-est } C]_{2}\left[\mathrm{NP} d_{2}\right.$-expensive $\left.\left.\left.t_{1}\right]\right]\right]$
b. $\quad\left[\left[2\left[t_{2}\right.\right.\right.$-expensive $\left.\left.t_{1}\right]\right] \rrbracket^{\mathrm{g}}=\lambda d \lambda x[x$ is a $d$-young student from $\mathrm{g}(1)]$
c. $\quad C \subseteq\{x: \exists d \exists 1[x$ is $d$-expensive $\wedge \mathrm{g}(1)(x)]\}$
d. $2^{\text {nd }}$ Step
e. cake ${ }_{1}[\text {-est } C]_{2}$ [John bought Mary [DP a [NP $d_{2}$-expensive $\left.\left.t_{1}\right]\right]$
f. $\quad C \subseteq\{f: \exists d \exists x[$ John bought Mary $x \wedge x$ is $d$-expensive $\wedge f(x)]\}$

The first movement step of the derivation of the DP-internal relative reading, (16a), is not semantically vacuous. The derivation of the DP-external relative reading, on the other hand, is excluded by economy principles since the QR of a DP-external constituent has no effect on semantics, (15a), until -est has QRed as well, (15c).

With indefinite superlative DPs we are technically able to derive both DPexternal and DP-internal relative readings by scoping -est DP-externally. At the same time, for DP-external relative readings DP-external scope of -est is not necessary: - est can be DP-internal and $C$ containing a set of cakes can be further restricted, e.g., to the set of cakes bought by someone for Mary, (11). Thus, a question arises: does the grammar prefer one way or the other for the derivation of the DP-external relative readings? Since the intermediate movement step in the derivation of the DP-external relative readings violates Scope Economy, I conclude that cross-linguistically DP-internal scope of -est is preferred for DP-external relative readings. -est scopes outside the DP only when necessary, that is, to derive DP-internal relative readings (as in (7) vs. (12)).

Accordingly, the derivation of the DP-external relative reading of the Polish example in (6b) involves DP-internal scope for -est. In the next section I show how

\footnotetext{
${ }^{4}$ This yields a reading that is somewhat similar to the absolute (There is an $x$ s.t. John bought $x$ for Mary and there is a degree $d$ s.t. $x$ is a $d$-expensive cake $\wedge \forall y[y \in C \wedge y \neq x \rightarrow \neg[y$ is a $d$-expensive cake]]), but the presupposition of uniqueness contributed by the definite determiner is missing.
} 
Relative readings of superlatives

the focus on the superlative adjective in (6b) ensures that -est is interpreted as taking DP-internal scope and $C$ is determined by the context given in the main clause. To get the actual relative reading of (3) and (6b), the fact that the head noun boy and the relative clause modifier combine intersectively has to be taken into account, and the denotation of the head noun has to be included in the specification of $C,\{x: \exists d$ $\exists y[x$ is a $d$-expensive cake $\wedge y$ got $x \wedge y$ is a boy $]\}$. The relative reading of the sentences in (3) and (6b) is thus a result of the contextual specification of $C$ by the immediate context, the relative clause and the noun that it modifies. In the next section I show that this context is what licenses the focus on the superlative adjective in the Polish example (6b).

\section{Focus and DP-internal -est}

\subsection{DP-external focus}

Focus effects on relative readings with DP-internal -est indicate that relative readings require a licensing context. The availability of such a context (explicitly or implicitly) is reflected in the focus structure of the sentence, and thus the placement of focus results in the different relative readings, see (2). At the same time, in the absence of focus the context can still constrain the comparison class as it happens in (3).

The mechanism of focus association introduced in Rooth 1992 has been widely adopted to model discourse congruence effects and to account for the contextual effects on the interpretation of quantificational operators - the value of the domain variable of a quantifier is determined with respect to the focus structure of the sentence (Rooth 1992, von Fintel 1994; Heim 1999; a.o.). The focus structure introduces a presupposition about the context, namely, that there is an antecedent $\beta$ whose ordinary semantic value is the subset of the focus value of the constituent $\alpha$, (17) (Rooth 1992: 88). The focus semantic value of $\alpha$ is the set of focus alternatives to $\alpha$ of the same semantic type as $\alpha$. The focus semantic value is generated in the presence of the focus operator $(\sim)$, which attaches to $\alpha$ at LF, and it is computed recursively from the level of the F-marked constituent to the level of $\sim$. The operator introduces the focal presupposition: 's domain variable $C$ ' denotes a subset of the focus alternative set of $\alpha,(18)$, and contains the ordinary semantic value of $\alpha$ and at least one other element (Rooth 1996: 279).

$$
\begin{aligned}
& \llbracket \beta \rrbracket^{o} \subseteq \llbracket \alpha \rrbracket^{f} \\
& C^{\prime} \subseteq \llbracket \alpha \rrbracket^{f}
\end{aligned}
$$

The restriction of the domain of quantificational operators (e.g., adverbs like always and only) taking sentential scope is determined by discourse congruence, but in the 
case of -est syntax plays a crucial role. -est introduces a presupposition that its domain argument $C$ is dependent on its second and third argument, which are in turn is determined by the scope of -est, (4). Therefore, it is the interaction between the focal presupposition and the presupposition of -est that effectively determines the contents of the comparison class $C$.

In (19a), the focus on the subject John (licensed by the implicit context) together with the syntax of -est and contextual specifications impose (congruent) requirements on $C,(19 \mathrm{~b}-\mathrm{f})$. For the right specification of the focal presupposition $\left(C^{\prime}\right.$ is the set of sets of individuals that someone bought for Mary, $\left.(19 \mathrm{c})\right), \sim$ attaches at the clausal level and the superlative DP QRs to Spec, TP, (19b). The presuppositions of -est require $C$ to be the set of cakes of a certain price, (19d). Focus association requires that $C$ is in an anaphoric relation with the restrictor of as specified in (17). The requirements imposed on $C$ by focus association, (19e), ${ }^{5}$ and by the presuppositions of -est, (19d), do not clash, so focus association contributes to the derivation of the relative reading in a meaningful way, $(19 \mathrm{f}){ }^{6}$

a. (Of all the boys who bought cakes for Mary, ...)

[John $]_{\mathrm{F}}$ bought Mary the most expensive cake.

b. [DP the [[-est C] $2 d_{2}$-expensive cake]] [TP1[ C ' $]\left[\right.$ TP2 $1[\mathrm{John}]_{\mathrm{F}}$ bought

c. $C^{\prime} \subseteq \llbracket \mathrm{TP}_{2} \rrbracket^{\mathrm{f}} \subseteq\{P: \exists y[P=\lambda x[y$ bought Mary $x]]\}$

Mary $\left.t_{1}\right]$ ]

d. $C \subseteq\{x: \exists d[x$ is a $d$-expensive cake $]\}$

e. $C \subseteq \cup \llbracket \mathrm{TP}_{2} \rrbracket^{f}$

f. $\llbracket(19 b) \rrbracket=1$ iff John bought Mary the unique cake of a certain price such that no other cake in the comparison class of relevant cakes of a certain price that someone bought is more expensive than that cake

In the presence of explicit context, (20a) (just like in the case of the relative clause in (3)), the context can constrain $C$ directly in accordance with -est's

\footnotetext{
${ }^{5}$ We can add a union operator to $C$ ' so that both $C$ ' and $C$ are of type $<e, t>$ to make an anaphoric link between them possible, $C \subseteq \cup \llbracket \alpha \rrbracket^{f}$. This is a stipulation, but it has been shown to be necessary for focus association with some quantificational expressions, e.g., the adverb always, (Rooth 1992, von Fintel 1994, Heim 1999). However, there is nothing in the system that explains what makes it available (Rooth 1999).

${ }^{6}$ Pancheva and Tomaszewicz 2012 and Tomaszewicz 2015b show that when -est remains DPinternal, only DP-external relative readings can be derived via -est's association with focus. In the different attempts at the derivation of DP-internal relative readings, either the contribution of focus is vacuous (cf. (12b)), or there is a clash with -est's presuppostitions, or unattested meanings are derived.
} 
Relative readings of superlatives

presuppositions: $C$ needs to be a subset of this set of cakes which is salient in the context, (20b). The meanings of (19a-b) and (20a) are identical.

(20) a. Of all the boys who bought cakes for Mary, ...

... John bought Mary [DP the [[-est $C]_{1} d_{1}$-expensive cake]]

b. $C \subseteq\{x: \exists d \exists y[x$ is a $d$-expensive $\wedge y$ bought Mary $x]\}$

The focus-sensitivity and context-dependency of relative readings of superlatives suggests that the focus structure of the sentence must be encoded at LF - it cannot be disregarded in the computation of the truth conditions of a superlative sentence. The obligatoriness of focus on the superlative adjective in the Polish relative clause in (6b) follows if the focus structure of the sentence is included in the LF. In fact, the interpretation of (6a) also results from both scope and focus structure, otherwise (6a) would be ambiguous, as explained below.

In Polish, due to the absence of the definite article, -est is free to scope DPexternally. If, as proposed in the previous section, the derivation of DP-external relative readings by scoping -est DP-externally violates Scope Economy, the sentence in (6a) should be ambiguous between (i) the DP-internal relative reading derived by DP-external scope for -est, and (ii) the DP-external relative reading derived by DP-internal scope for -est. The reason for the lack of this ambiguity is the fact that on the neutral intonation of the sentence, the nuclear stress falls on the constituent cake. The nuclear stress on cake easily allows for the interpretation of cake as narrow focus, which is compatible with (i), (21), but not with (ii) (in Tomaszewicz 2015b I present empirical evidence that if -est scopes DP-externally, the element that saturates its third argument must be F-marked).

(21) LF for (6a) (updated (7))

a. [[ $\left.\left.\sim C^{\prime}\right][\text { cake }]_{\mathrm{F}}\right][$-est $C] 21$ John bought Mary [DP $d_{2}$-expensive $\left.t_{1}\right]$

b. $C^{\prime} \subseteq \llbracket[\text { cake }]_{\mathrm{F}} \rrbracket^{f} \subseteq\{$ chocolate, candy, apple, cake,...

c. $C \subseteq\{f: \exists d \exists x$ [John bought Mary $x \wedge x$ is $d$-expensive $\wedge f(x)]\}$

d. $C \subseteq \llbracket[\text { cake }]_{\mathrm{F}} \rrbracket^{f}$

Now the reason why the DP-internal relative reading of (6a) is not available for (6b) is that once the superlative adjective is marked as narrow focus, the constituent cake cannot be accented and interpreted as a focus. The focus on the superlative adjective results in -est itself being focused. 


\subsection{Focus on -est itself}

In (6b) the focus on the superlative adjective indicates that -est must be taking DPinternal scope, because this focus requires a licensing context involving alternatives to most expensive. Sharvit and Stateva 2002 observe that when most itself is focused, both the absolute and the relative readings are available in English. The example in (22) is parallel to the one given by Sharvit and Stateva to illustrate the relative reading when the primary focus is on the superlative: ${ }^{7}$

(22) Bill bought a $\$ 30$ cake, Ann bought a $\$ 50$ cake and

John bought the $[\mathrm{MOST}]_{\mathrm{F}}$ expensive cake.

Intuitively, the comparison in (22) is of the different prices of cakes that different people bought. However, while the first two clauses specify the prices of cakes in the comparison class for the superlative, that is, the degrees that are members of the set in (23b), the superlative is a quantifier over degrees and so the superlative sentence does not specify a member of this set. Instead, as Sharvit and Stateva propose, we have to assume that $\$ 30$ and $\$ 50$ are of the same type as [-est $C$ ] and denote functions such as $\lambda P \lambda x[\$ 30(P)(x)]$, where $P$ is of type $<d,<e, t>>$.

(23) a. How expensive a cake did each person buy?

b. $\{d: \exists x[x$ is a $d$-expensive cake $\wedge y$ bought $x \wedge y \in\{$ Bill, Ann, John $\}]\}$

c. $\{D: \exists x[D=D(\lambda d \lambda z[z$ is $d$-expensive $])(x) \wedge x$ is a cake $\wedge y$ bought $x \wedge$

$$
y \in\{\text { Bill, Ann, John }\}\}
$$

The assumption that $\$ 30$ and $\$ 50$ are of the same type as [-est $C$ ] is unnecessary if we consider that the licensing context for the placement of focus on the superlative expression involves the implicit subquestion in (24SQ).

(24) Q: How expensive a cake did each person buy?

$S Q:$ As for every person, did that person buy the most/least expensive cake? (implicit)

A: (22).

\footnotetext{
${ }^{7}$ Sharvit and Stateva 2002 provide the following example ((78b), p.485):

(i) Bill climbed a $2000 \mathrm{ft}$ mountain and Mary climbed a $3000 \mathrm{ft}$ mountain. John climbed the high-EST mountain.

They note that in (i) the first syllable of highest is the most prominent phonetically, but in examples with most/least those elements bear the main stress. They propose that this is the default focus pattern for superlative sentences in English, but, as my discussion will show, this pattern is appropriate only with a suitable licensing antecedent.
} 
Relative readings of superlatives

A subquestion provides a partial answer to the explicit higher question $Q$ and answering all of the subquestion entailed by $\mathrm{Q}$ provides a complete answer to $\mathrm{Q}$ (Roberts 1998, 2004; a.o.). Consider Büring's (2003) example in (25) where the answers A1 and A2 are both appropriate as answers to the question Q, but, in fact, they directly answer the implicit subquestions SQ1 and SQ2.

(25) Q: How many (of the 74) abstracts got accepted?

(Büring 2003)

SQ1: Did any abstracts get accepted?

$\mathrm{Al}$ : (Yes,) $\mathrm{SOME}_{C T}$ abstracts $\mathrm{DID}_{F}$ get accepted.

$$
\mathrm{L}+\mathrm{H}^{*} \quad \mathrm{H}^{*} \mathrm{~L}-\mathrm{L} \%
$$

SQ2: Did most abstracts get accepted?

A2: (Yes,) MOST MT $_{C}$ abstracts DID $_{F}$ get accepted.

$$
\mathrm{L}+\mathrm{H}^{*} \quad \mathrm{H}^{*} \mathrm{~L}-\mathrm{L} \%
$$

In (25A1) the topic some contrasts with any in the implicit subquestion, but does not contrast with any explicit element in the preceding discourse. In (22) the focus on most evokes an implicit contrast set \{most expensive, least expensive\}, while there is no directly contrasting element in the preceding context. The context in (22) provides a licensing antecedent for the focus on most by implicitly evoking the alternative set, (24). On Rooth's semantics of focus, there has to be an anaphoric relationship between the restrictor of the focus interpretation operator $\sim$ and its antecedent, a discourse object $\beta,(17)$. The ordinary semantic value of $\beta$ must be a subset of the focus semantic value of $\alpha$ (they must have matching types). The set denoted by a question must be a subset of the alternative set provided by the answer. Declarative sentences in ordinary discourse typically do not follow explicit questions, but an implicit (sub)question can be made salient either by prior discourse or by the answer itself (Stalnaker 1978; Roberts 1996; Büring 2003; Beaver and Clark 2008; a.o.). Note how the superlative sentence in (26A) is not felicitous as a direct answer to the question (26Q) uttered without prior context. What makes (26A) felicitous in the discourse is the accommodation of the subquestion (26SQ) by the interlocutors upon hearing the answer (26A). The context in (26SQ) provides a suitable antecedent for the focus on [-est C], (26d).

(26) Q: How expensive a cake did John buy?

SQ: Did John buy the most expensive cake? (implicit)

a. $\beta=\llbracket[$-est $C] \rrbracket^{\circ}$

A: John bought the $[\mathrm{MOST}]_{\mathrm{F}}$ expensive cake.

b. LF for (26A): John bought the $\left[[\text {-est } C]_{\mathrm{F}}\left[\sim C^{\prime}\right]\right] d$-expensive cake.

c. $\llbracket[\text {-est } C]_{\mathrm{F}} \rrbracket^{f}=\{[$-est $C]$, [least $\left.C]\right\}$

d. $\llbracket[-$ est $C] \rrbracket^{\circ} \subseteq \llbracket[-$ est $C] \mathrm{F} \rrbracket^{f}$ 
In (26A) the focus on most specifies the comparison class $C$ only indirectly - via the obligatory presence of the (implicit) context that licenses the focus. This result is fully compatible with the optionality of focus effects with DP-internal -est (as shown at the beginning of this section in (19-22), with DP-internal -est, $C$ can be specified by association with focus, (19), or it can be set purely by context, (20)).

However, a further question arises: when [-est $C$ ] itself is focused, are the relative readings necessarily derived by the contextual setting of $C$ or is focus association also possible? The answer is that focus association is possible insofar as it is possible for a sentence to contain more than one focus. Since each sentence contains one nuclear stress marking the constituent that can be interpreted as narrow focus, how can we test if there are more foci in the sentence? A standard way to identify foci is through question answer congruence - the new information is Fmarked and the question provides an antecedent for $\sim$ 's restrictor $C$ '.

A multiple wh-question such as 'Who ate what?' on its pair-list interpretation can be answered in two ways: (i) for each person, list what they ate, (ii) for each food, list who ate it. As identified by Jackendoff (1972) the answer 'Fred ate the beans' will have a different intonation pattern with each strategy. With (i) there is a fall-rise pitch accent on Fred and a fall on beans. With (ii) the fall rise is on beans and the fall on Fred. The fall-rise pitch accent in English is seen as a grammatical realization of a contrastive topic and the falling accent as the realization of focus (Kadmon 2001; Buring 2003; Wagner 2012; Constant 2012). The prosodic realization of a contrastive topic is what indicates the presence of a subquestion identifying each strategy: (i) 'What about FRED? What did HE eat?'; (ii) 'What about the BEANS? Who ate THEM?' (Roberts 1996; Buring 2003).

The response to the multiple wh-question in (27Q) needs to provide new information on the identity of cake buyers and on the characteristics of cakes. Following Wagner 2012 and Constant 2012, I take contrastive topics to be Fmarked and interpreted by a focus operator. The question (27Q) licenses focus on Bill, Ann and John and on $\$ 30$ and $\$ 50$ in (27A). The subquestion (27SQ) licenses focus on most in (27A). In Wagner 2012 when two focus operators are present and one outscopes another, the constituent that associates with the focus operator taking wider scope is the contrastive topic, and the one associating with the focus operator taking narrow scope is the focus. In (27A) the F-marked John is the contrastive topic and -est associates with it (a possibility predicted on Wagner's 2012 and Constant's 2012 accounts).

\section{Q: Who bought which cake?}

SQ: Did anyone buy the most expensive cake? (implicit)

A: $[\text { Bill }]_{\mathrm{F}}$ bought the $[\$ 30]_{\mathrm{F}}$ cake, $[\mathrm{Ann}]_{\mathrm{F}}$ bought the $[\$ 50]_{\mathrm{F}}$ cake and $[\mathrm{John}]_{\mathrm{F}}$ bought the $[\mathrm{most}]_{\mathrm{F}}$ expensive cake. 
Relative readings of superlatives

In Polish, a multiple wh-question such as (28a) can be answered in two ways to provide a pair-list answer. In $(28 \mathrm{~b})$ the whole superlative DP is fronted and accented as a contrastive topic and the subject Jan is in a right-peripheral focus position. In (28c) the in-situ subject Jan is accented as a contrastive topic and is thus F-marked. In both $(28 \mathrm{~b}-\mathrm{c})$, the F-marked constituents correspond to the wh-phrases, and the availability of F-marking at the syntax-phonology interface correlates with the availability of relative readings. In (28c) Jan is not accented as a focus, but it is interpreted as F-marked and is thus available for focus association.

a. Który chłopiec jakie ciastko kupił? Which boy which cake bought 'Which boy bought which cake?'

b. $[\text { Najdroższe ciastko }]_{1-\mathrm{F} / \mathrm{CT}} t_{2}$ kupił $t_{1} \quad[\mathrm{JAN}]_{2-\mathrm{F}}$. most-expensive cake bought Jan

'Jan bought the most expensive cake.'

c. $[\mathrm{Jan}]_{\mathrm{F} / \mathrm{CT}}$ kupił [najDROŻsze $]_{\mathrm{F}}$ ciastko. Jan bought most-expensive cake 'Jan bought the most expensive cake.'

It follows from the recursive definition of focus in Rooth 1992, 1996 that all foci are bound by the first $\sim$ operator in whose scope they appear. But when a phrase is scoped to a level where it escapes one focus operator, it can be bound by the next one. The LF that derives the DP-external reading via DP-internal -est and focus association is shown in (29a). The superlative DP QRs out of the scope of $\sim_{8}$ which interpretes the F-feature on the subject, (19b). This configuration allows for the presence of another $\sim$-operator to interpret the focus on [-est $C], \sim 9$. -est can thus itself be focused, (29b), and still associate with the focus in TP1 bound by $\sim 8,(29 c-$ d).

$$
\begin{aligned}
& \text { a. } \operatorname{LF} \text { for }(28 \mathrm{c}) \\
& {\left[\mathrm{DP}\left[\left[[-e s t C]_{\mathrm{F} 1}\left[\sim_{9} C^{\prime}{ }_{9}\right]\right] 2\left[\mathrm{NP} t_{2} \text {-expensive cake }\right]\right]\right]\left[\mathrm{TP} 1\left[\sim_{8} C^{\prime}{ }_{8}\right] 1\right.} \\
& \left.\left[\text { TP2 }[\mathrm{Jan}]_{\mathrm{F} 2} \text { bought } t_{1}\right]\right]
\end{aligned}
$$

b. $\llbracket[-$ est $C] \rrbracket^{\circ} \subseteq \llbracket[-$ est $\left.C] \mathrm{F}\right]^{f}$

c. $C^{\prime}{ }_{8} \subseteq \llbracket \mathrm{TP}_{2} \rrbracket^{f} \subseteq\{P: \exists y[P=\lambda x[y$ bought $x]]\}$

d. $C \subseteq \cup \llbracket \mathrm{TP}_{2} \rrbracket^{f}$

Summing up, in this section I have shown that the focus association account of relative readings makes the right predictions for the two empirical facts from English and Polish. Focus is optional for the derivation of relative readings in a language where -est remains DP-internally in the presence of the definite determiner, which accounts for the English data in (2) and (3). Focus is obligatorily on the superlative adjective in the Polish example in (6b) because it ensures that 
-est is interpreted DP-internally and allows for a contextual specification of $C$ (with DP-external -est, $C$ is determined by the F-marked argument of -est and cannot be set purely contextually). Moreover, the focus on the superlative adjective in (6b) supports the arguments in Section 3 that for the derivation of the DP-external relative readings in Polish, -est has to be DP-internal (the derivation of DP-external relative readings by DP-external scope of -est is precluded by Scope Economy). Finally, I have shown that when the superlative adjective is focused, association with another focus may still be possible - as long as another constituent in the sentence can be F-marked.

\section{Conclusions}

In this paper, I have argued that the superlative morpheme -est scopes outside of the superlative DP in Polish only for the derivation of the relative readings set with respect to the DP-internal constituent. The DP-external scope for -est is available in the first place because the Polish superlative DP lacks a definite determiner. The derivation of the relative readings set with respect to a DP-external constituent is precluded in Polish by Scope Economy. Such readings are derived with -est remaining DP-internally in both Polish and English.

What guarantees DP-internal scope for -est in Polish is the focus on the superlative adjective itself. I have shown that this focus placement follows from the context-dependency of -est. I have argued that once the focus structure is taken to be obligatorily included in the computation of the truth conditions of a superlative sentence, we account both for the optionality of focus in the derivation of relative readings in English and for the obligatoriness of the focus on the superlative adjective for the derivation of relative readings with DP-internal -est in Polish.

\section{References}

Beaver, David and Brady Clark. 2008. Sense and Sensitivity: How Focus Determines Meaning. Oxford: Wiley-Blackwell.

Bhatt, Rajesh and Shoichi Takahashi. 2007. Direct comparisons: Resurrecting the direct analysis of phrasal comparatives. In T. Friedman \& M. Gibson (eds), Semantics and Linguistic Theory (SALT) 17, 19-36, Ithaca, NY: Cornell University. http://dx.doi.org/10.3765/salt.v0i0.2958

Bošković, Željko and Jon Gajewski. 2009/2011. Semantic correlates of the NP/DP Parameter. In Suzi Lima, Kevin Mullin and Brian Smith (eds.), North-Eastern Linguistic Society (NELS) 39, 121-135. Cornell University, Ithaca: CreateSpace Independent Publishing Platform. 
Relative readings of superlatives

Büring, Daniel. 2003. On D-trees, beans and B-accents. Linguistics and Philosophy 26, 511-545. http://dx.doi.org/10.1023/a:1025887707652

Cinque, Guglielmo. 2010. The Syntax of Adjectives. Cambridge: The MIT Press.

Constant, Noah. 2012. English rise-fall-rise: A study in the semantics and pragmatics of intonation. Linguistics and Philosophy 35(5). 407-442. http://dx.doi.org/10.1007/s10988-012-9121-1

Coppock, Elizabeth and David Beaver. 2014. A superlative argument for a minimal theory of definiteness. In Todd Snide (ed.), Semantics and Linguistic Theory (SALT) 24, 177-196. Cornell University, Ithaca: CLC Publications. http://dx.doi.org/10.3765/salt.v24i0.2432

Farkas, Donka and Katalin É. Kiss. 2000. On the comparative and absolute readings of superlatives. Natural Language and Linguistic Theory 18, 417-455. http://dx.doi.org/10.1023/a:1006431429816

von Fintel, Kai. 1994. Restrictions on quantifier domains. Doctoral Dissertation, University of Massachusetts, Amherst: Graduate Student Linguistics Association (GLSA).

Fox, Danny. 2000. Economy and Semantic Interpretation. Cambridge: MIT Press.

Gawron, Mark. 1995. Comparatives, superlatives, and resolution. Linguistics and Philosophy 8, 333-380. http://dx.doi.org/10.3765/salt.v2i0.3031

Heim, Irene. 1985. Notes on comparatives and related matters. University of Texas, Austin: Manuscript.

Heim, Irene. 1999. Notes on superlatives. MIT, Cambridge: Manuscript.

Jackendoff, Ray. 1972. Semantic Interpretation in Generative Grammar. MIT Press.

Kotek, Hadas, Yasutada Sudo, Edwin Howard, and Martin Hackl. 2011. Three readings of most. In Ashton, Neil, Anca Chereches and David Lutz (eds.), Semantics and Linguistic Theory (SALT) 21, 353-372. Cornell University, Ithaca: CLC Publications. http://dx.doi.org/10.3765/salt.v21i0.2621

Kadmon, Nirit. 2001. Formal Pragmatics. Blackwell.

Pancheva, Roumyana and Barbara M. Tomaszewicz, 2012. Cross-linguistic differences in superlative movement out of nominal phrases. In Nathan Arnett and Ryan Bennett (eds.), West Coast Conference on Formal Linguistics (WCCFL) 30, 292-302. Somerville, MA: Cascadilla Proceedings.

Reinhart, Tanya. 2006. Interface Strategies: Optimal and Costly Computations. Cambridge: MIT Press.

Roberts, Craige. 1996. Information structure in discourse: Towards an integrated formal theory of pragmatics. In J. H. Yoon and Andreas Kathol (eds.), OSU Working Papers in Linguistics 49: Papers in Semantics, 91-136. Columbus: Ohio State University. 
Roberts, Craige. 1998. Focus, the flow of information, and Universal Grammar. In Peter Culicover and Louise McNally (eds.), The Limits of Syntax, 109-60. New York: Academic Press.

Roberts, Craige. 2004. Context in dynamic interpretation. In Laurence R. Horn and Gregory Ward (eds.), The Handbook of Pragmatics, 197-219. Malden, MA: Blackwell Publishing.

Rooth, Mats. 1985. A theory of focus interpretation. University of Massachusetts, Amherst: Doctoral Dissertation.

Rooth, Mats. 1992. A theory of focus interpretation. Natural Language Semantics 1, 75-116. http://dx.doi.org/10.1007/bf02342617

Rooth, Mats. 1996. Focus. The Handbook of Contemporary Semantic Theory, ed. Shalom Lappin. Oxford: Blackwell.

Rooth, Mats. 1999. Association with focus or association with presupposition? In Peter Bosch and Rob van der Sandt (eds.), Focus: Linguistic, cognitive, and computational perspectives, 232-246. Cambridge: Cambridge University Press.

Ross, John Robert. 1964. A partial grammar of English superlatives. University of Pennsylvania: MA Thesis.

Sharvit, Yael and Penka Stateva. 2002. Superlative expressions, context, and focus, Linguistics and Philosophy 25, 453-504. http://dx.doi.org/10.1023/a:1020875809794

Stalnaker, Robert C. 1978. Assertion. Pragmatics - Syntax \& Semantics 9, ed. by Peter Cole, 315-332. New York: Academic Press.

Szabolcsi, Anna. 1986. Comparative superlatives. MITWPL 8, 245-66.

Tomaszewicz, Barbara. 2015a. Definiteness and degree morphology. In Joanna Blaszczak, Dorota Klimek-Jankowska, Krzysztof Migdalski (eds.), How Categorical are Categories? New Approaches to the Old Questions of Noun, Verb, and Adjective. Studies in Generative Grammar [SGG] 122, 197-232. Berlin: Mouton de Gruyter.

Tomaszewicz, Barbara. 2015b. Superlative ambiguities: a comparative perspective. Ph.D. Dissertation, University of Southern California.

Wagner, Michael. 2012. Contrastive topics decomposed. Semantics and Pragmatics 5(8). 1-54. http://dx.doi.org/10.3765/sp.5.8

Barbara Tomaszewicz

Tilburg University

PO BOX 90153

5000 LE Tilburg

Netherlands

barbara.tomaszewicz@gmail.com 